STUDI

FRANCESI

\section{Studi Francesi}

Rivista quadrimestrale fondata da Franco Simone

177 (LIX | III) | 2015

Varia

\title{
Aa. Vv., Romans à clés. Les ambivalences du réel, sous la direction d'Anthony Glinoer et de Michel Lacroix
}

\section{Michel Arrous}

\section{(2) OpenEdition}

\section{Journals}

Édition électronique

URL : http://journals.openedition.org/studifrancesi/1360

DOI : 10.4000/studifrancesi. 1360

ISSN : 2427-5856

Éditeur

Rosenberg \& Sellier

\section{Édition imprimée}

Date de publication : 1 décembre 2015

Pagination : 597

ISSN : 0039-2944

\section{Référence électronique}

Michel Arrous, «Aa. Vv., Romans à clés. Les ambivalences du réel, sous la direction d'Anthony Glinoer et de Michel Lacroix », Studi Francesi [En ligne], 177 (LIX | III) | 2015, mis en ligne le 01 décembre 2015, consulté le 06 janvier 2021. URL : http://journals.openedition.org/studifrancesi/1360 ; DOI : https:// doi.org/10.4000/studifrancesi. 1360

Ce document a été généré automatiquement le 6 janvier 2021.

\section{(c) (†) $\odot$}

Studi Francesi è distribuita con Licenza Creative Commons Attribuzione - Non commerciale - Non opere derivate 4.0 Internazionale. 


\title{
Aa. Vv., Romans à clés. Les ambivalences du réel, sous la direction d'Anthony Glinoer et de Michel Lacroix
}

\author{
Michel Arrous
}

\section{RÉFÉRENCE}

AA. VV., Romans à clés. Les ambivalences du réel, sous la direction d'Anthony GLINOER et de Michel LACRoIX, Presses Universitaires de Liège, 2014, pp. 203.

1 En présentant ce recueil, Anthony Glinoer et Michel Lacroix rappellent que, si le corpus des fictions à clés est vaste, il est peu étudié, du moins pour la période postérieure à la Révolution française. Depuis le répertoire historique de Drujon (1888), l'étude de ce genre littéraire a été délaissée, sans doute à cause d'une production souvent médiocre. Néanmoins, depuis une décennie, on note un intérêt nouveau (voir, par exemple, de Sean Latham, The Art of Scandal. Modernism, Libel Law, and the Roman à Clef, 2003, dont on lira l'introduction aux pp.21-42), stimulé par la mode de la bio-fiction, forme dérangeante et parfois honnie car elle s'apparente à la recherche d'un succès de scandale, comme on l'a vu lors de récents procès. Le roman à clés suppose un lectorat capable de reconnaître les individus cachés derrière les noms de la fiction; mais s'il arrive que le lecteur soit aveugle ou peu au fait de l'actualité, les chroniqueurs, et pas seulement ceux de la presse littéraire, ont tôt fait de l'informer. Sous l'Ancien Régime, les romans à clefs comportaient une clef imprimée; de nos jours, la presse et la télévision commentent et décryptent à l'attention des ignorants qui n'ont pas le bonheur de faire partie du public initié. On se reportera à l'enquête menée par Mathilde BOMBART pour la période 2002-2012 (Romans à clés: une pratique illégitime au filtre de la critique littéraire des journaux, pp. 43-65). Pour certains, un des enjeux de cette 
pratique, qui n'est d'ailleurs peut-être pas le plus décisif, c'est sa référentialité littéraire; pour d'autres, négliger l'effet des clés entraînerait un appauvrissement de la lecture puisqu'on se priverait d'une forme de réflexivité. Quel statut accorder à la notion de roman à clés? Les études rassemblées privilégient quelques-unes de ses modalités, particulièrement les fictions de la vie littéraire. Bien que celle de Michel LACROIX (Imaginaire, légendaire, fictif: romans à clés et fiction de la vie littéraire, pp. 11-20), envisage deux cas du xxe siècle (Victor-Lévy Beaulieu dans L'Énigme du retour (2009), de Dany Laferrière, et Cocteau dans Les Faux-monnayeurs), elle intéressera les dixneuviémistes car elle examine la réécriture de légendes littéraires autour des figures d'écrivains légendaires ou imaginaires, réécriture qui suppose un lecteur apte au décryptage et capable de repérer les connotations et les décalages. À partir de la notion d'illusio littéraire, dans le cas de la fictionnalisation du motif cénaculaire, Anthony GLINOER et Vincent LAISNEY reviennent sur les raisons du discrédit qui a frappé le roman à clés et sur sa double ambivalence, à la fois fictionnelle et fonctionnelle (Les illusions perdues, ou les romans cénaculaires, pp. 67-85). Dans la fiction du cénacle (Balzac, les Goncourt, Zola) se retrouvent les mêmes éléments et les mêmes procédés référentiels, au moyen des clés, et en même temps se mettent en place les éléments d'une nouvelle légende. Denis SAINT-AMAND a choisi une autre mise en scène du milieu littéraire français du XIX $x^{e}$ siècle qui fait basculer la réalité du côté de la fiction, sous la forme de microrécits, dans la lignée de La Lorgnette de Monselet (1857) (Figurations et médiogrammes. Les micro-fictions du "Petit Bottin des Lettres et des Arts", pp. 86-97). Dans ses notices fictionnelles, cet inventaire satirique se livre à une désacralisation de l'écrivain et de l'artiste dont la portée n'est efficace que pour les connaisseurs du champ littéraire fin de siècle. Rachilde serait-elle la reine du genre? À coup sûr, répond Michael R. FINN dans Plaisir d'offrir, joie de recevoir. Le roman à clef décadent et Rachilde (pp. 98-112), car, entre 1880 et 1890, elle apparait comme personnage dans sept romans, qui ne sont pas tous des portraits à charge, et même dans un pamphlet venimeux; quant à ses œuvres, elles fourmillent de personnages facilement reconnaissables (Catulle Mendès, Maurice Barrès, etc.) Du roman à clés on passe à cette «espèce de roman à clés» que pourrait être celui de Proust, du moins accessoirement, voire accidentellement dit Elisheva ROSEN (La pratique des clés au prisme de la "Recherche", pp. 113-130). En dépit de Proust déclarant que dans son livre «il n'y a pas un seul personnage "à clefs"», bien des lecteurs ont relevé les marques d'une écriture cryptique et le jeu des identifications a commencé dès la parution de l'œuvre. Plus que le goût des clés, c'est le processus de référenciation et ses dysfonctionnements qui caractérisent la pratique biaisée de Proust, comme le montrent ces exemples de codage: Morel réglant ses comptes avec M. de Charlus à coups de "petites chroniques transparentes», le duc de Guermantes redoutant que des écrivains ne mettent sa femme dans leurs ouvrages, ou, subtile provocation, deux occurrences bien connues: l'une concernant le personnage de Charles Swann et son modèle présumé Charles Haas, l'autre, la plus célèbre, à propos des Larivière, les parents millionnaires de Françoise, personnes réelles dont le narrateur se porte garant. Signalons, parmi les autres contributions concernant le $\mathrm{xx}^{\mathrm{e}}$ siècle, et parce qu'elle confirme en quelque sorte la "vanité des romans à clefs» (P. Assouline) et leur mode de lecture réducteur, celle d'Anne STRASSER ("Les Mandarins", les clés pour le dire, pp. 131-144): Beauvoir met en scène la vie littéraire avec ses écrivains fictifs qu'on a voulu confronter à des acteurs de l'histoire littéraire, dans un récit qui est plus un roman autobiographique qu'un roman à clefs. Il est donc nécessaire de 
dépasser le simpliste examen du cryptage pour apprécier toutes les postulations des romans à clés. 